http://jmscr.igmpublication.org/home/ ISSN (e)-2347-176x ISSN (p) 2455-0450 crossref DOI: https://dx.doi.org/10.18535/jmscr/v9i1.34

\title{
Tuberculosis and Guillian Barre Syndrome - A Rare Presentation of AMAN Variant
}

\author{
Urvashi Khan ${ }^{1}$, Anil Kumar ${ }^{2}$, Gauresh Singh ${ }^{3}$ Ashok Kumar \\ ${ }^{1}$ MBBS, Post graduate student, Department of Internal Medicine, Santosh Medical College \& Hospitals \\ ${ }^{2}$ DNB, IDCCM, IFCCM, MNAMS, Senior consultant \& Head, Department of Critical Care Medicine, \\ Santosh Medical College \& Hospitals \\ ${ }^{3} \mathrm{MD}$, Assistant Professor, Department of Anaesthesiology and Critical Care Medicine, Santosh Medical \\ College \& Hospitals \\ ${ }^{4} \mathrm{MD}$, Professor \& Head, Department of Medicine, Santosh Medical College \& Hospitals \\ Corresponding Author \\ Dr Anil Kumar
}

Authors

Department of Anaesthesiology \& Critical Care Medicine, Santosh Medical College Hospital, Ghaziabad, UP., India

\section{Background}

A 57-year female resident of U.P. presented with acute-onset quadriparesis that had developed during last 5 days along with breathlessness. After extensive clinical, laboratory and radiological evaluation, the patient was diagnosed with an acute motor axonal neuropathy (AMAN) variant of Guillain-Barre Syndrome (GBS). Treatment was given as per the protocol, simultaneously diagnosed to have tubercular meningitis for which first-line Anti-Tubercular Therapy was administered. During the follow-up at 6 months, the patient was asymptomatic, she had no residual weakness and could walk without support, and tuberculosis had resolved. Many infectious agents have been known to trigger GBS, but only a few cases of GBS and Tuberculosis have been reported. This association needs to be evaluated and must be kept in mind in TB prevalent nations.

\section{Introduction}

Guillain-Barre Syndrome is a rare autoimmune inflammatory demyelinating polyneuroradiculopathy seen after bacterial or viral infections and sometimes even after vaccinations. The incidence of GBS is about 1$2 / 100,000$ per year ${ }^{(1)}$. Subtypes are described based on electrophysiological patterns, the most common being Acute Inflammatory Demyelinating Polyneuropathy (AIDP) and rarer ones being Acute Motor Axonal Neuropathy (AMAN).

Tuberculosis is rampant in India and myriad presentations have been reported. Neurological manifestations of tuberculosis include meningitis, tuberculomas, brain abscesses, and radiculomyelitis ${ }^{(2)}$.

Tuberculosis and GBS were first reported to occur together in 1966 and a few cases have been reported since, but the nature of the association between the two is not yet clear. Reported earlier 
was a case involving a young boy who presented with acute onset quadriparesis and who was subsequently found to have GBS and disseminated tuberculosis.

\section{Case Report}

A 57-year-old female presented with acute-onset weakness that developed in both lower limbs 5 days prior. Weakness had started abruptly and started to progress from lower limbs. Breathlessness gradually increased leading to acute respiratory arrest and Significant desaturation, requiring Intubation and mechanical ventilation. She had received antibiotics previously and was sent to our Hospital for further management. There was no sensory, bowel, or bladder involvement. She had no history of antecedent diarrhea, upper respiratory tract symptoms, or a history of recent vaccination for influenza or meningococcus.

On examination, she had quadriparesis with a power grade of 0 (according to the Medical Research Council (MRC) Scale for Muscle Strength) in the lower limbs. The deep tendon reflexes were diminished. Cranial nerve examination normal. No sensory involvement, normal papillary and fundus examination. The rest of the general physical and systemic examination was unremarkable.

Laboratory tests in the form of complete blood counts revealed $(\mathrm{Hb} 14.2 \mathrm{~g} / \mathrm{dL})$, while the total leucocyte count was increased and platelet count were within the normal range. The erythrocyte sedimentation rate (ESR) was elevated $(100 \mathrm{~mm}$ in the first hour). Albumin: globulin reversal was noted with an albumin level of $3.6 \mathrm{~g} / \mathrm{dL}$ and a globulin level of $3.12 \mathrm{~g} / \mathrm{dL}$. The rest of the liver and kidney function tests were normal. A chest Xray revealed no abnormality. Nerve Conduction Velocity study revealed axonal motor neuropathy in both lower limbs. Analysis of cerebrospinal fluid suggestive of albuminocytologic dissociation, elevated protein levels $(90 \mathrm{mg} / \mathrm{dL}$ ) with a $120 \mathrm{mg} / \mathrm{dl}$ glucose level and normal cell counts. Magnetic Resonance Imaging (MRI) of the brain and spine was normal. Xray lumbosacral spine showed spondylosis with mild compression fracture at L3 and $\mathrm{X}$ ray abdomen was insignificant. Overall, neurological findings suggested GBS.

Exhaustive tests were conducted to determine the triggers and etiology of the accompanying fever and headache. Serology was negative for HIV, Hepatitis B and C, Cytomegalovirus (CMV), and Epstein-Barr virus (EBV). She also received Intravenous immunoglobulin therapy $(0.4 \mathrm{gm} / \mathrm{kg}$ over 5 days) along with rest supportive care and physiotherapy. Gradually on day 3 patients had some improvement in power, she was gradually extubated on day 8 after fulfilling the weaning criteria and clinical recovery in terms of muscle power \& strength. During the course of illness, pateint had severe headache and developed one episode of involuntary movements involving all four limbs, with Uprolling of eyeballs with frothing from mouth. CT Head done no significant finding and lumbar puncture planned after consent. Cerebrospinal fluid (CSF) revealed protein $92 \mathrm{mg} / \mathrm{dl}$, sugar $78 \mathrm{mg} / \mathrm{dl}$ with all mononuclear cells, Adenosine Deaminase (ADA) was 72. Patient was considered likely to have tuberculosis and was started on category I ATT along with steroids. During hospitalization, weakness continued to improve and the fever subsided. The patient was discharged but closely followed. At the follow-up at 6 months, the patient was afebrile, pedal edema had resolved, and weakness had considerably improved with a muscle strength grade of 5 in all 4 limbs. Steroids had been tapered off by this time. 


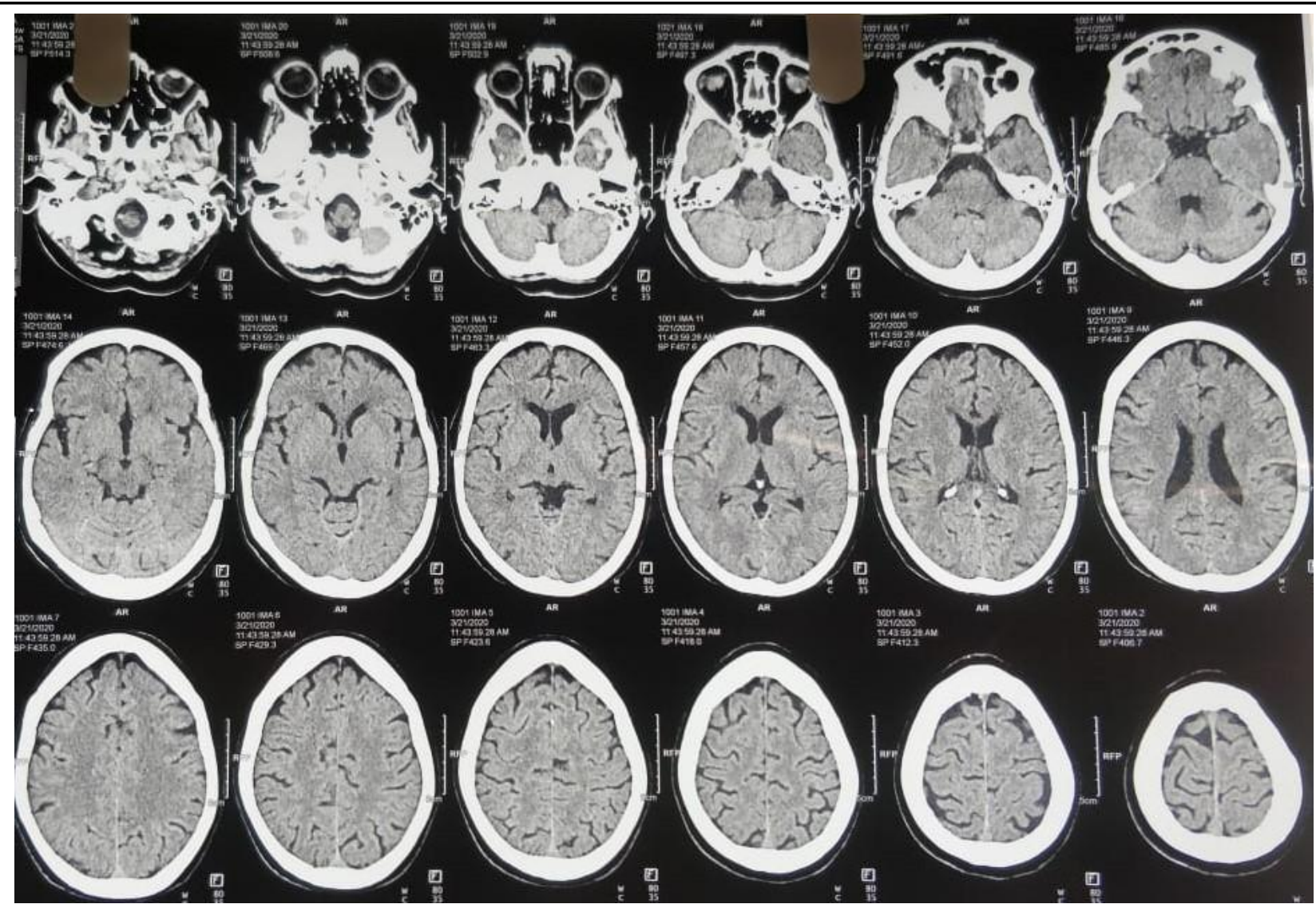

NCCT head, nothing significant apart from age related changes.

Table 1 Summary of reported cases of GBS and Tuberculosis.

\begin{tabular}{|c|c|c|c|}
\hline Author and year (ref no.) & Diagnosis & Treatment & Outcome \\
\hline $\begin{array}{l}\text { Vyravanathan et al. } 1983 \\
\text { (8) }\end{array}$ & $\begin{array}{l}\text { Pulmonary tuberculosis } \\
\text { with GBS }\end{array}$ & ATT and physiotherapy & Recovered completely \\
\hline Soehardy et al . 2005 (6) & $\begin{array}{lr}\begin{array}{l}\text { Pulmonary } \\
\text { and GBS }\end{array} & \text { tuberculosis } \\
\text { Variant) } & \end{array}$ & ATT and IV IG & Recovered Completely \\
\hline De la Torre et al .2010 (5) & $\begin{array}{l}\text { Extrapulmonary } \\
\text { Tuberculosis (Cervical } \\
\text { Lymph Node) with GBS }\end{array}$ & ATT and IV IG & 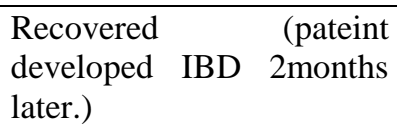 \\
\hline Taha et al .2012 (7) & $\begin{array}{l}\text { Pulmonary Tuberculosis } \\
\text { with GBS (AIDP) }\end{array}$ & d IV IG & Recovered completely \\
\hline Canham et al .2014 (4) & $\begin{array}{l}\text { Pulmonary tuberculosis } \\
\text { with pericardial effusion } \\
\text { with GBS }\end{array}$ & ATT and IV IG & $\begin{array}{lr}\text { Difficulty } & \text { walking,with } \\
\text { restrictive } & \text { ankle } \\
\text { movement, } & \text { constrictive } \\
\text { pericarditis } & \\
\end{array}$ \\
\hline Mohta S et al .2017 (9) & $\begin{array}{l}\text { Disseminated tuberculosis } \\
\text { with GBS }\end{array}$ & ATT, and Plasmapheresis & $\begin{array}{lr}\text { Constrictive } & \text { pericarditis } \\
\text { without } & \text { functional } \\
\text { disability } & \end{array}$ \\
\hline
\end{tabular}

AIDP, acute inflammatory demyelinating neuropathy, AMSAN acute motor sensory axonal neuropathy;

ATT antitubercular therapy; IBD inflammatory bowel disease ; IV IG , intravenous immunoglobulin.

\section{Discussion}

In our case, patient initially presented to us as a case of GBS, with lower limb weakness along with CSF albuminocytological dissociation and nerve conduction velocity. Patient was given ventilator support, empirical antibiotics, antiviral and supportive care. Our patient received iv Immunoglobulins as one of the recommended treatment. Our patient had significant recovery post IV IG, and later got extubated. Episode of seizure and its workup led to the diagnosis of tubercular meningitis based of elevated ADA 
Levels, sugars and protein. Our patient responded very well to anti tubercular therapy for tubercular meningitis along with physiotherapy and early iv immunoglobulins for the GBS.

Tuberculosis and GBS were first reported to occur together in 1966 and a few cases have been reported since, but the nature of the association between the two is not yet clear. Since studies have noted improvement even up to 4 weeks after the onset of weakness ${ }^{(3)}$, the patient was treated with intravenous immunoglobulin with significant improvement. most of the reported cases with the association has tuberculosis prior to the onset of weakness or on Anti tubercular therapy. AMAN variant of GBS, is the second most common variant after AIDP in India. ${ }^{(9)}$

The pathogenesis of GBS likely immune mediated, and delayed cell mediated immunity in tuberculosis could be the possible mechanism leading to autoimmunity and damage to nerves.

\section{Conclusion}

In tuberculosis prevalent nations, our case highlights the possibility of tuberculosis leading to GBS AMAN Variant. This association needs further investigation, evaluation, research and possible pathogenesis.

No conflict of Interest.

\section{References}

1. Yuki N, Hartung HP, N Engl J Med. 2012 Jun 14;366(24):2294-304.

2. Neurological complications of tuberculosis: some unusual manifestations. Kocen RS, Parsons M Q J Med. 1970 Jan; 39(153):17-30.

3. Hughes RA, Swan AV, van Doorn PA. Intravenous immunoglobulin for Guillain-Barre syndrome. Cochrane Database Syst Rev. 2014; CD002063.
4. Canham EM, Iseman MD. Guillain-Barre syndrome related to pulmonary tuberculosis. Ann Am Thorac Soc. $2014 ;$ 11:855-857.

5. de la Torre RG, Moris G, Martinez DP, Montes IC. Guillain-Barre syndrome, tuberculosis and inflammatory bowel disease: A multiple association. Int Arch Med. 2010; 3:15.

6. Soehardy Z, Yuhanisa A, Thein SS, Rohana AG, Fauzi AR, Norlinah MI, Hamidon BB, Rozaidi SW. AMSAN variant of Guillain Barre syndrome progressing to chronic inflammatory demyelinating polyneuropathy in a patient with Marfan's syndrome and pulmonary tuberculosis. Med J Malaysia. 2005; 60: 655-656.

7. Taha AA, Tee KH. Guillain-Barre syndrome associated with pulmonary tuberculosis. BMJ Case Rep. 2012; 13:2012.

8. Vyravanathan S, Senanayake N. GuillainBarre syndrome associated with tuberculosis. Postgrad Med J. 1983; 59:516-517.

9. Srikant Mohta, Manish Soneja, Surabhi vyas, Wasim Khot tuberculosis and Guillian Barre Syndrome: A Chance Association. 